\title{
The Role of Carbohydrates in Active Osmotic Adjustment in Apple under Water Stress
}

\author{
Zhongchun Wang and Gary W. Stutte ${ }^{1}$ \\ Department of Horticulture, University of Maryland, College Park, MD 20742
}

Additional index words. carbon partitioning, sorbitol, water relations, water stress, Malus domestica

\begin{abstract}
Greenhouse grown 2-year-old potted 'Jonathan' apple trees (Malus domestica Borkh.) were subjected to various levels of water stress in February. Midday leaf water potential $\left(\psi_{w}\right)$, leaf osmotic potential $\left(\psi_{\mathrm{s}}\right)$, soluble sugars, and starch contents of mature leaves were measured throughout the development of water stress to determine whether active osmotic adjustment could be detected and whether carbohydrates were involved. Active adjustments of 0.6 MPa were observed 3 and 5 days, respectively, after water stress was initiated. Leaf turgor potential $\left(\psi_{\mathrm{p}}\right)$ could not be maintained through the osmotic adjustment when $\psi_{w}$ dropped below -1.6 MPa. Sorbitol, glucose, and fructose concentrations increased while sucrose and starch levels decreased significantly as water stress developed, strongly suggesting that sugar alcohol and monosaccharide are the most important osmotica for adjustment. Sorbitol was a primary carbohydrate in the cell sap and accounted for $>\mathbf{5 0 \%}$ of total osmotic adjustment. The partitioning of newly fixed $\mathrm{W}$-labeled photosynthates in mature leaves was not affected by water stress immediately after the $30-\mathrm{min}^{14} \mathrm{CO}_{2}$ treatment. All the W-labeled carbohydrates decreased in the labeled leaves very rapidly after ${ }^{14} \mathrm{CO}_{2}$ labeling. The decrease in ${ }^{14} \mathrm{C}$-sorbitol was greater than the decrease in other carbohydrates under both well-watered and stressed conditions. After 24 hours of water stress, however, the percentage of ${ }^{14} \mathrm{C}$-sorbitol increased while the percentages of sucrose, starch, glucose, and fructose decreased significantly with increasing levels of stress. The ratio of ${ }^{14} \mathrm{C}$-sorbitol in leaves with $\psi_{w}=-3.5 \mathrm{MPa}$ to leaves with $\psi_{\mathrm{w}}=-0.5 \mathrm{MPa}$ was significantly higher than that of ${ }^{14} \mathrm{C}$-sucrose, ${ }^{14} \mathrm{C}$-glucose, W-fructose, or ${ }^{14} \mathrm{C}$-starch.
\end{abstract}

Water deficit can cause serious losses in most crop plants, including apple trees in arid regions. Water stress has been shown to affect many plant processes, for example, cell growth (Acevedo et al., 1971), ABA synthesis (Cornish and Zeevaart, 1984), stomatal opening (Henson et al., 1989), $\mathrm{CO}_{2}$ assimilation (Robinson et al., 1988), and sugar accumulation (Handa et al., 1983). The responses of plants to water stress have been reviewed by Hsiao (1973), Morgan (1984), Jones et al. (1985), and Turner (1986).

Many plants develop morphological and physiological adaptations to water stress. Some examples of adaptation to water stress are rapid completion of ontogeny, leaf rolling, reduced leaf size, low stomatal conductance, and high root : shoot ratios (Landsberg and Jones, 1981; Morgan, 1984). Through osmotic adjustment, some species actively accumulate solutes during water stress and decrease $\psi_{\mathrm{S}}$ so that $\psi_{\mathrm{p}}$ remains above levels critical for cellular expansion (Hsiao, 1973; Hsiao et al., 1976; Turner, 1979). Long-term osmotic adjustment to periodic stresses and short-term diurnal adjustment both provide an effective mechanism to maintain sufficient turgor for stomatal opening and photosynthetic productivity (Lakso, 1983). Inorganic cations, organic acids, amino acids, and sugars, which are the primary osmotica, bring about osmotic adjustment through either internal synthesis or uptake of osmotically active substances (Munns and Weir, 1981; Nicolas et al., 1985; Rhodes et al., 1986; Turner, 1979). There is little doubt that soluble sugars can contribute to osmotic adjustment. In agronomic crops an increase in soluble sugar concentration in response to water stress has been found in roots and leaves (Cutler et al., 1977; Drossopoulos et al., 1987; Turner et al., 1978). However, low levels of solute in sorghum (Newton et al., 1986) and of total

Received for publication 31 Oct. 1991. Accepted for publication 11 Mar. 1992. The cost of publishing this paper was defrayed in part by the payment of page charges. Under postal regulations, this paper therefore must be hereby marked advertisement solely to indicate this fact.

'Current address: Bionetics Corp. Mail code Bio 3. Kennedy Space Center, FL 32899 . carbohydrate in maize (Thankur and Rai, 1980) have been associated with increasing water stress.

Apple (Lakso et al., 1984), orange [Citrus sinensis (L.) Osb.] (Fereres et al., 1979), peach [Prunus persica (L.) Batsch] (Steinberg et al., 1989), cherry (Prunus spp.) (Ranney et al., 1991), and grape (Vitis vinifera L.) (Düring, 1985) have been shown to adjust osmotically in response to drought. Adjustments varying from 0.5 to $3 \mathrm{MPa}$ have been found, but only 0.2 to $0.5 \mathrm{MPa}$ was from active adjustment. The remainder was due to passive dehydration (Davies and Lakso, 1979; Fereres et al., 1979; Goode and Higgs, 1973). However, as high as 2.5 MPa seasonal active osmotic adjustment has been observed in mature field-grown McIntosh apple trees from June to September (Lakso et al., 1984). Fanjul and Rosher (1984) and Goode and Higgs (1973), suggested that photosynthetic accumulation or sugar concentration contributes to this adjustment. The results of Davies and Lakso (1979), however, failed to show active adjustment in the field-grown and potted trees on a seasonal basis. They found that the soluble carbohydrate content of apple leaves did not significantly change during the day. Syvertsen and Albrigo (1980) also failed to observe osmotic adjustment in 20-year-old orange trees. In the literature reviewed, most experiments concentrated on total solutes as osmotica with few reports on total sugar and even fewer on individual sugar level and the role of starch.

In the woody Rosaceae species, sorbitol is the major photosynthetic product and is translocated to developing sink tissues (Bieleski, 1969; Hansen and Grauslund, 1978). Sorbitol, accounting for $\approx 60 \%$ to $80 \%$ of the $\mathrm{C}$ translocated in Rosaceae (Webb and Burley, 1962), is reported to be produced in mature leaves and transported to young leaves (Bieleski and Redgwell, 1985). Because sorbitol constitutes a major carbohydrate component in apple trees, we hypothesize that it has an important role in osmotic adjustment during water deficit. The objectives

\footnotetext{
Abbreviations: $\psi_{\mathrm{p}}$, leaf turgor potential; $\psi_{\mathrm{s}}$, leaf osmotic potential; $\psi_{\mathrm{w}}$, leaf water potential; DPM, disintegration per minute; MEOH, methanol; Pn, photosynthesis; RWC, relative water content; Rs, stomatal resistance.
} 
of this study were to investigate the extent of osmotic adjustment of mature leaves in drought-exposed potted apple trees, the roles that individual carbohydrates play in active osmotic adjustment, the importance of sorbitol in total osmotic adjustment, and the causes of active osmotic adjustment.

\section{Materials and Methods}

Plant materials and treatments. The experiments were carried out in February in a greenhouse using 2-year-old 'Jonathan'/M7 apple trees grown in 3.8-liter pots that were $17 \mathrm{~cm}$ in diameter and 17-cm deep and filled with Professional Growing Medium 300-S (Pro-gro Products, Elizabeth City, N.C.). Variation in midday light intensity was 800 to $1000 \mu \mathrm{mol} \cdot \mathrm{m}^{-2} \cdot \mathrm{s}^{-1}$ photosynthetic photon flux density for all the treatments, and no supplemental lights were provided. Midday air temperature in the greenhouse was 20 to $25 \mathrm{C}$. All plants experienced several cycles of water deficit that resulted in midday turgor loss of young leaves, but did not induce terminal bud set or leaf abscission before treatments were started. All trees were watered equally before being treated. Four water stress treatments were initiated on 3 Feb. on actively growing plants with $\approx 40$ leaves each on extension shoots. In the nonstressed treatment (control), 1 liter water was applied to each pot every day and $\psi_{\mathrm{w}}$, was maintained between -0.5 and $-1.0 \mathrm{MPa}$ at midday under sunny conditions. In the mildly stressed treatment, plants were watered at one-half the volume of water given to control plants. Water potential reached -1.0 to $-1.5 \mathrm{MPa}$ at midday, 1 day after the initiation of water stress, and then was maintained at that level throughout the experiment by applying small amounts of water as needed. The moderately stressed plants were watered at one-fourth the volume of water given to control plants. Here, $\psi_{\mathrm{w}}$, reached -2.0 to $-2.5 \mathrm{MPa}$ at midday 2 days after the initiation of water stress and then was maintained at that level throughout the experiment by misting the soil as needed. The severely stressed plants were not watered during the experiment and $\psi_{\mathrm{w}}$, was $<-3.0 \mathrm{MPa}$. The plot design was a randomized complete block with three single-tree replications per treatment.

Photosynthesis $(P n)$ and stomatal resistance measurements (Rs). A mature leaf from a vigorously growing shoot was inserted into a 1/4-liter leaf chamber of LI-6200 (LI-COR, Lincoln, Neb.) portable photosynthesis system befor $\phi_{w}$ measurement. The leaf was allowed to photosynthesize inside the chamber under full sunlight. Pn was determined when $\mathrm{CO}_{2}$ concentration dropped $10 \mathrm{ppm}$ after a steady rate of $\mathrm{CO}_{2}$ use had been obtained, which typically required 5 to $30 \mathrm{sec}$ per sample, depending on the photosynthetic rate. The leaf area inside the chamber was determined with a LI-3000 portable area meter (LI-COR).

${ }^{14} \mathrm{CO}_{2}$-labeling. One growing branch of each tree was sealed in a clear plastic bag at 11:30 AM on 4 Feb. Previously generated ${ }^{14} \mathrm{CO}_{2}\left(3.7 \times 10^{6} \mathrm{~Bq}\right)$ was injected into each bag within $1 \mathrm{~min}$ for all the treatments, and the leaves were allowed to photosynthesize for $30 \mathrm{~min}$ in full light before the bags were removed. The labeled leaves were harvested as described below.

$\psi_{\mathrm{w}}$ and relative water content $(R W C)$ measurement. Six mature leaves were harvested from each tree immediately after the bags were removed and then again 24,48 , and $96 \mathrm{~h}$ later. The leaves from each tree were separated into two groups of three leaves each. One group of leaves was used to determine RWC (Barrs and Weatherley, 1962). The other group was used for $\psi_{\text {w }}$ measurements by use of a pressure bomb. The amount of water lost during $\psi_{\mathrm{w}}$ determinations was not measured. Then the samples were sealed into plastic bags, put into an ice chest, and transported to the laboratory for $\psi_{\mathrm{s}}$, and individual carbohydrate determinations.

$\psi_{s}$ and soluble sugar analysis. The leaves were frozen and stored at $-70 \mathrm{C}$ until analyzed. The sap of thawed leaves was expressed with a garlic press. Ten $\mu$ l of sap was used for $\psi_{\mathrm{s}}$ determination with a Wescor 5500 vapor pressure osmometer (Wescore, Logan, Utah). Osmotic potential was adjusted to $100 \%$ RWC to eliminate passive tissue dehydration using the following equation: $\psi_{\mathrm{s}}$ at $100 \% \mathrm{RWC}=\left(\right.$ measured $\left.\psi_{\mathrm{s}} \times \mathrm{RWC}\right) / 100$. Turgor potential was calculated from the difference between $\psi_{\mathrm{w}}$ and $\psi_{s}$. The contribution of the apoplastic water to $\psi_{s}$ was not independently determined so $\psi_{\mathrm{s}}$ included the contributions of both symplastic and apoplastic water. About $1 \mathrm{ml}$ remaining sap was centrifuged, and the supernatant was diluted lo-fold with $18 \mathrm{MOhm}$ deionized water. One milliliter of diluted sap was filtered through $0.2 \mu \mathrm{m}$-nylon sterile filters into 1.5 -ml dram vials. Ten microliters were injected into a Shimadzu HPLC (Kyoto, Japan) for individual sugar analysis. A Shimadzu RID$6 \mathrm{~A}$ refractive index detector at $30 \mathrm{C}$ was used to quantify sugar content following separation on a Bio-Rad HPX-87C carbohydrate column $(300 \times 7.8 \mathrm{~mm})$ at $85 \mathrm{C}$ using helium-sparged, $18 \mathrm{MOhm}$, distilled, deionized $\mathrm{H}_{2} \mathrm{O}$ at $0.6 \mathrm{ml} \cdot \mathrm{min}^{-1}$ as the mobile phase. The individual carbohydrates were confirmed by comparing retention times of $10 \mu \mathrm{l}$ standard sample containing $(\mu \mathrm{g}) 20$ sucrose, 20 glucose, 20 fructose, and 20 sorbitol. The concentrations of carbohydrates were recalculated to $100 \%$ RWC using the equation given for $\psi_{s}$ calibration to eliminate the impact of passive tissue dehydration.

Starch analysis. The residue of expressed leaves was dried, weighed, and extracted four times with $10 \mathrm{ml} \mathrm{80 \%} \mathrm{methanol}$ $(\mathrm{MEOH})$. The four MEOH supernatants were discarded and the pellet retained. Five milliliters $18 \mathrm{MOhm}$ water was added to the pellet, and the resulting suspension was boiled for $30 \mathrm{~min}$ to swell starch granules. After cooling at room temperature, the solution was digested with $1 \mathrm{ml} 1 \%$ amyloglucosidase (EC 3.2.1.3) (Sigma Chemical Co., St. Louis, Lot no. 24F-0314) at $55 \mathrm{C}$ in a water bath overnight. The digest was centrifuged and filtered, and then $10 \mu 1$ of digest was injected into a Shimadzu HPLC for glucose determination as described for the soluble sugar analysis. Starch concentration was determined by converting the glucose equivalent to starch.

${ }^{14}$ C-soluble carbohydrate counting. An Advantac SF-2120 (Osaka, Japan) fraction collector was used to collect each soluble sugar in a scintillation vial following HPLC separation. Then, $3 \mathrm{ml}$ of Beckman Ready Gel liquid scintillation cocktail was added to each vial and ${ }^{14} \mathrm{C}$-labeled sorbitol, sucrose, glucose, and fructose fractions were counted via a LKB 1219 Rackbeta (Turku, Finland) liquid scintillation counter.

${ }^{14} C$-starch analysis. A $100-\mu l$ aliquot of the digest was injected into a Shimadzu HPLC, the glucose fraction collected, and ${ }^{14} \mathrm{C}$-glucose counted. The disintegration per minute (DPM) of ${ }^{14} \mathrm{C}$-starch was calculated from the equivalency of ${ }^{14} \mathrm{C}$-glucase after starch digestion.

$\psi_{\text {s }}$ contribution of sorbitol. To determine the contribution of sorbitol to total osmotic adjustment, standard sorbitol solutions ranging from 0 to $100 \mathrm{mg} \cdot \mathrm{ml}^{-1} \mathrm{H}_{2} \mathrm{O}$ were prepared and the osmotic potential of each solution was measured using a Wescor 5500 vapor pressure osmometer. The contribution of sorbitol in total osmotic adjustment was calculated following the equation:

$$
\frac{\left(\psi_{s} \mathrm{sa}-\psi_{\mathrm{s}} s b\right)}{\left(\psi_{\mathrm{s}} a-\psi_{\mathrm{s}} b\right)} \times 100
$$

where $\psi_{s}$ sa represents $\psi_{s}$ of the standard sorbitol solution at 
concentrations found under water stress when $\psi_{\mathrm{w}}$ was from -1.3 to $-4.0 \mathrm{MPa} ; \quad \psi_{\mathrm{s}}$ sbepresents $\psi_{\mathrm{s}}$ of the standard sorbitol solution at concentrations found under well-watered conditions when $\psi_{\mathrm{w}}$ was about $-1.0 \mathrm{MPa} ; \psi_{\mathrm{s}}$ a represents $\psi_{\mathrm{s}}$ of leaf samples under water stress when $\psi_{\mathrm{w}}$ was from -1.3 to $-4.0 \mathrm{MPa}$; $\psi_{\mathrm{s}} \mathrm{b}$ represents $\psi_{\mathrm{s}}$ of leaf samples under well-watered conditions when $\psi_{\mathrm{w}}$ was about $-1.0 \mathrm{MPa}$ at midday. The expression $\left(\psi_{\mathrm{s}} \mathrm{a}\right.$ $-\psi_{\mathrm{s}} \mathrm{b}$ ) of a sample was considered as total osmotic adjustment imposed by all the osmotica.

\section{Results and Discussion}

As water stress developed, $\psi_{\mathrm{s}}$ decreased gradually (Fig. 1). Active osmotic adjustment of $0.6 \mathrm{MPa}$ was detected in mature leaves of potted 'Jonathan' apple trees within 3 days of the initiation of water stress as $\psi_{\mathrm{w}}$ decreased from -0.6 to -2.6 $\mathrm{MPa}$. Turgor potential also declined as water potential decreased. When $\psi_{w}$ exceeded $-1.6 \mathrm{MPa}$, however, active osmotic adjustment in $\psi_{\mathrm{S}}$ maintained $\psi_{\mathrm{P}}>1 \mathrm{MPa}$, but was insufficient to sustain full turgor when $\psi_{\mathrm{w}}$ dropped below -1.6 $\mathrm{MPa}$. After 5 days of water stress, the relationship between $\psi_{\mathrm{w}}$, $\psi_{\mathrm{s}}$, and $\psi_{\mathrm{p}}$ showed similar trends, but with as much as $1.3 \mathrm{MPa}$ active osmotic adjustment detected as $\psi_{\mathrm{w}}$ decreased to -4.0
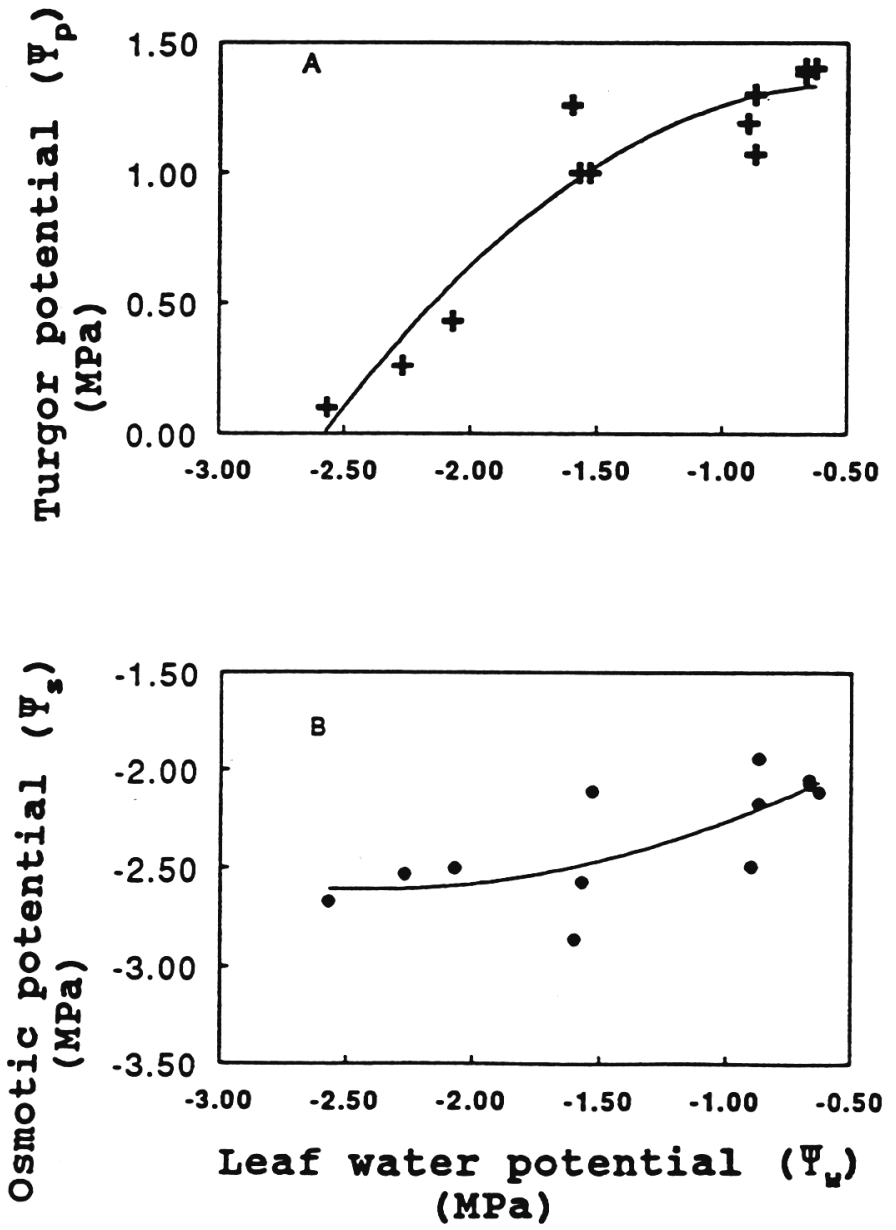

Fig. 1. Relationships between $\psi_{\mathrm{w}}$, and $\psi_{\mathrm{s}}$ or $\psi_{\mathrm{p}}$ of mature apple leaves 3 days after the imposition of various levels of water stress. All the values were adjusted to $100 \% \mathrm{RWC}$ and $\psi_{\mathrm{P}}$ was the difference between $\psi_{\mathrm{w}}$ and $\psi_{\mathrm{s}} \times \psi_{\mathrm{s}}$ : $\mathrm{y}=-1.61+0.82 \mathrm{x}+0.17 \mathrm{x}^{2}, R^{2}=$ $0.55 * *(P<0.01) . \psi_{\mathrm{p}}: \mathrm{y}=1.26-0.31 \mathrm{x}-0.31 \mathrm{x}^{2}, R^{2}=0.92 * *$ $(P<0.01)$.
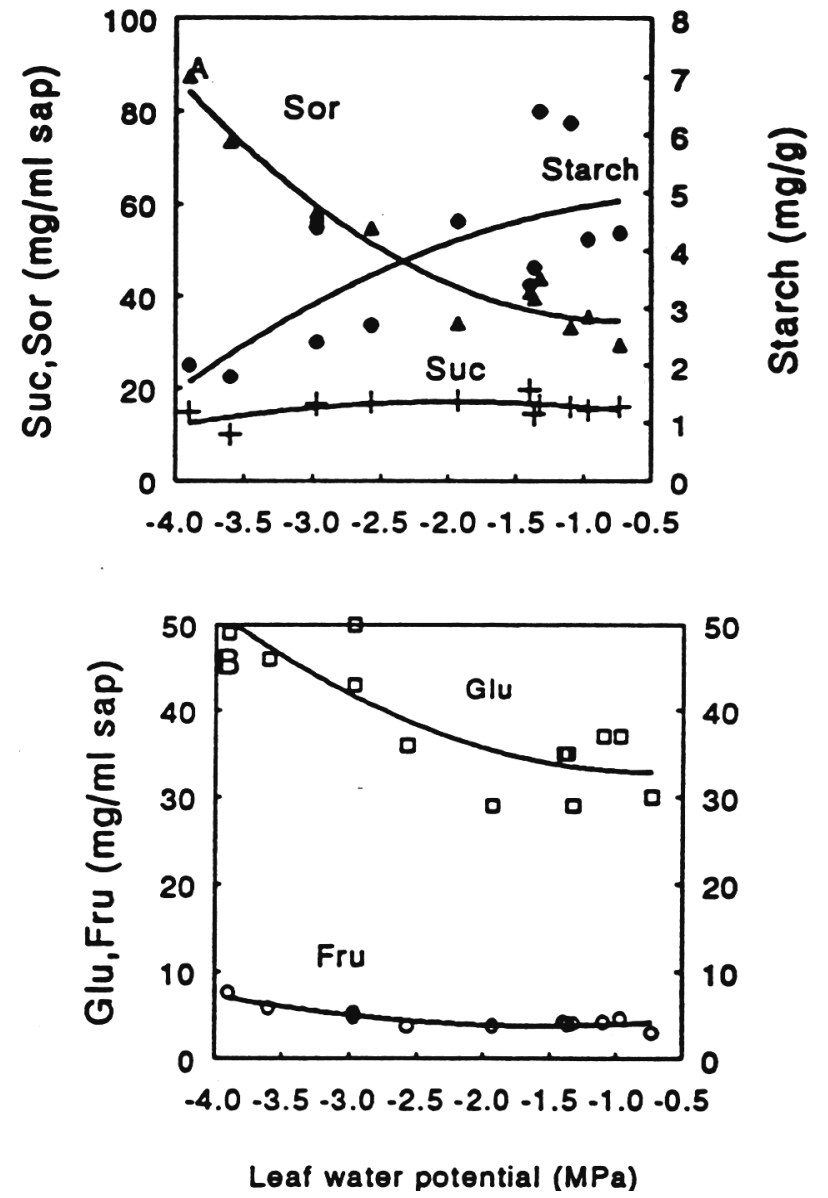

Fig. 2. Effects of water stress on carbohydrate concentrations in mature apple leaves 5 days after the imposition of various levels of water stress. The concentrations of carbohydrates were adjusted to $100 \%$ RWC. (A) Sorbitol (Sor): $\mathrm{y}=36.85+6.58 \mathrm{x}+4.82 \mathrm{x}^{2}, R^{2}$ $=0.94 * *(P<0.01)$. Sucrose $($ Sue $): \mathrm{y}=12.43-4.85 \mathrm{x}-1.24 \mathrm{x}^{2}$, $R^{2}=0.37 *(P<0.05)$. Starch: $\mathrm{y}=4.96-0.03 \mathrm{x}-0.22 \mathrm{x}^{2}, R^{2}$ $=0.53 * *(P<0.01)$. (B) Glucose (Glu): $\mathrm{y}=33.73+2.45 \mathrm{x}+$ $1.74 \mathrm{x}^{2}, R^{*}=0.69 * *(P<0.01)$. Fructose (Fru): y $=5.21+$ $1.85 \mathrm{x}+0.60 \mathrm{x}^{2}, R^{2}=0.79 * *(P<0.01)$.

MPa (data not shown). No active osmotic adjustment was found in young leaves (data not shown).

The amount of active osmotic adjustment we observed in 'Jonathan' is similar to that reported by Davies and Lakso (1979) for field-grown 'McIntosh'/M2 trees on a daily basis, but is substantially lower than the 2.0 to $2.5 \mathrm{MPa}$ seasonal active osmotic adjustment reported for mature 'McIntosh' by Lakso et al. (1984). Our results contrast with those of Davies and Lakso (1979) who found no seasonal adjustment in potted apple trees. Hsiao et al. (1976) reported that a lowering of osmotic potential of $>0.2$ or $0.3 \mathrm{MPa}$ through dehydration should reduce $\psi_{\mathrm{p}}$ to nearly zero for many crop species. In contrast, a lowering of the same amount of osmotic potential through solute accumulation would still maintain cell turgor and cell volume as well as turgor-mediated processes. Our results indicate that the capacity for osmotic adjustment in apple leaves is limited under a rapidly developed high level of water stress. When water potential was above $-1.6 \mathrm{MPa}, \psi_{\mathrm{P}}$ was maintained $>1 \mathrm{MPa}$ through active adjustment, but this active adjustment was insufficient to maintain $\psi_{\mathrm{p}}$ at $1 \mathrm{MPa}$ level when water potential was below -1.6 MPa (Fig. 1). This result is consistent with 
our observation that plants started to show slight wilting in young and old leaves when $\psi_{\mathrm{w}}$ declined to about $-2.0 \mathrm{MPa}$ at midday. However, mature leaves in the middle of the shoots did not show any wilting until plants were stressed to $\psi_{\mathrm{w}}$ values below $-2.5 \mathrm{MPa}$.

In contrast, the concentration of individual carbohydrates in young leaves did not change with water stress and no active adjustment in young leaves was detected. This lack of change may be due to the use of carbohydrates imported by young leaves for growth metabolism, not solute accumulation (Lakso et al., 1984). The lack of osmotic adjustment in the young apple leaves and shoot tip is effective in reducing leaf area in response to stress while the mature leaves adjust to the stress to maintain photosynthetic production (Lakso, 1983). These results are in agreement with those reported by Swietlik and Miller (1983) for PP333-treated apple seedlings. In contrast, Steinberg et al. (1989) reported active osmotic adjustment in young, but not in mature, peach leaves.

The use of potted greenhouse trees as models for studying environmental stresses has been questioned because water stress develops much more rapidly in this system than in field-grown trees. We attempted to precondition the trees before treatment to simulate field conditions. However, water stress still developed in this experiment within 1 to 2 days after the initiation of treatments due to the limited soil volume and low waterholding capacity of the soil. We do not know how this affected the osmotic responses of the leaves.

The variation in the reported occurrence and intensity of active osmotic adjustment in apple could be associated with cultivar, time of year, previous stress level, rate of stress development, and duration of stress. In preliminary experiments (unpublished) using 4-year-old potted 'Staymen'/M7a, we observed $0.8 \mathrm{MPa}$ of active osmotic adjustment in response to water stress in October, but no active osmotic adjustment in the same trees in August. Further, the technique used to separate active from passive osmotic adjustment may affect the accuracy of results since rehydrating the leaf to $100 \% \mathrm{RWC}$ may result in a change of solute concentration during the several hours of rehydration (Lakso et al., 1984). Measuring $\psi_{\mathrm{s}}$ in early morning when RWC is believed to be $100 \%$ may also be inappropriate because leaves usually do not show osmotic adjustment in the early morning (Lakso et al., 1984). The method we used may minimize these shortcomings since active osmotic adjustment was consistently detected.

The concentrations of individual carbohydrates in mature leaves responded differently to the development of water stress. The concentrations of sorbitol, glucose, and fructose increased as $\psi_{\mathrm{s}}$ become more negative, while the concentrations of starch and sucrose decreased significantly (Fig. 2). The relationships between $\psi_{s}$ and the concentrations of individual carbohydrates showed similar trends, except that the changes in sucrose were statistically nonsignificant as $\psi_{\mathrm{s}}$ became more negative (Fig. 3). Sorbitol was the most abundant soluble carbohydrate (30 to 90 $\left.\mathrm{mg} \cdot \mathrm{ml}^{-1} \mathrm{sap}\right)$ in mature leaves. Highly negative correlations between $\psi_{\mathrm{w}}$ and sorbitol : sucrose ratio $\left(R^{2}=0.85^{* *}\right)$ or sorbitol : starch ratio $\left(R^{2}=0.90 * *\right)$ were also observed (Fig. 4). The high ratio of sorbitol to both sucrose and starch, as water stress developed, suggests the possible conversions of starch and/or sucrose to sorbitol. When the contribution of sorbitol to total osmotic adjustment was quantified (Fig. 5), sorbitol accounted for $\approx 60 \%$ to $70 \%$ of total change in solute potential under low to moderate stress, i.e., when $\psi_{\mathrm{w}}$ was more than $-2.5 \mathrm{MPa}$. However, under severe water stress, when $\psi_{\mathrm{w}}$ was
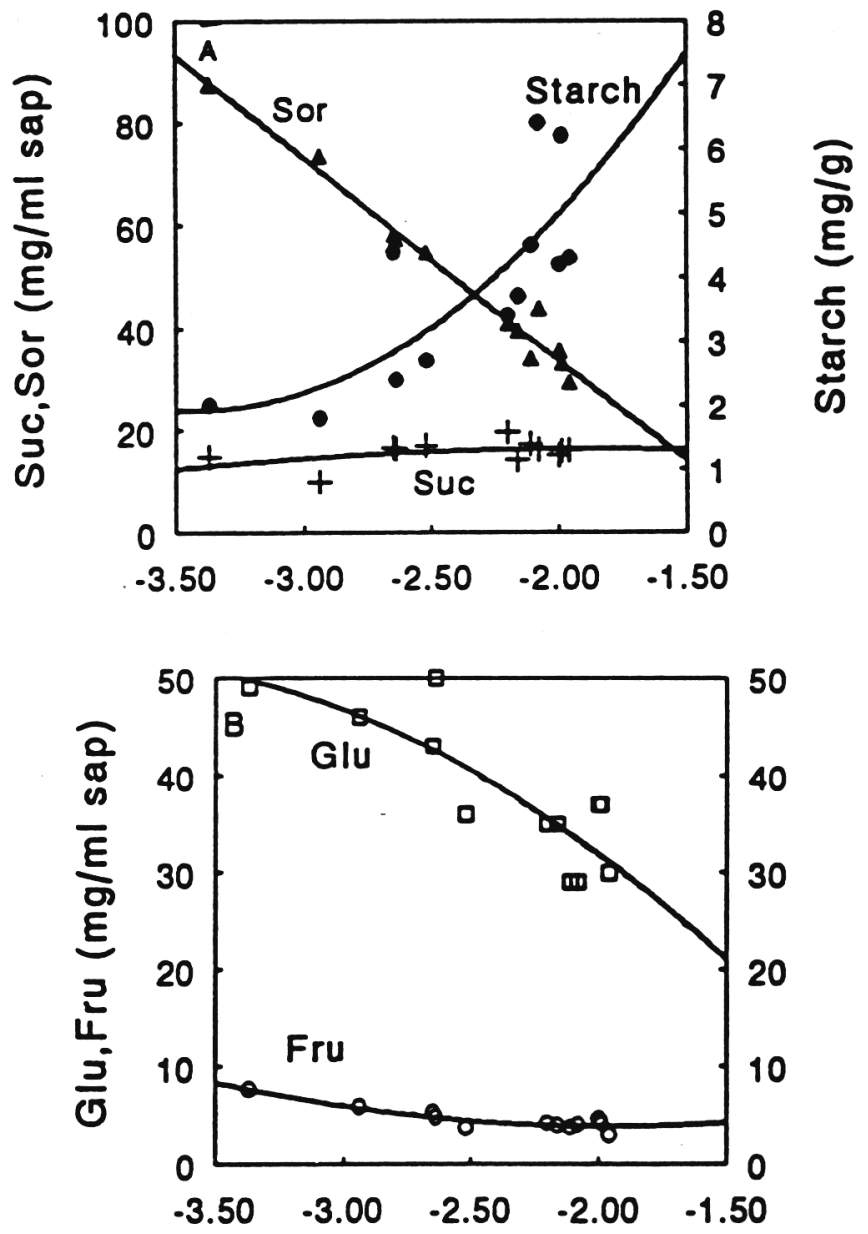

Leaf osmotic potential (MPa)

Fig. 3. Relationships between $\psi_{s}$ and concentrations of individual carbohydrates in mature apple leaves 5 days after the imposition of various levels of water stress. The concentration and $\psi_{s}$ were adjusted to $100 \%$ RWC. (A) Sorbitol (Sor): $y=-43.02-37.78 x$ $+0.34 \mathrm{x}^{2}, R^{*}=0.98 * *(P<0.01)$. Sucrose (Suc): $\mathrm{y}=11.07-$ $5.67 \mathrm{x}-1.50 \mathrm{x}^{2}, R^{2}=0.18(P>0.05)$. Starch: $\mathrm{y}=19.40+$ $10.16 \mathrm{x}+1.48 \mathrm{x}^{2}, R^{2}=0.59 * *(P<0.01)$. (B) Glucose (Glu): y $=-25.57-38.23 \mathrm{x}-4.71 \mathrm{x}^{2}, R^{2}=0.71 * *(P<0.01)$. Fructose (Fru): $\mathrm{y}=11.20+7.45 \mathrm{x}+1.90 \mathrm{x}^{2}, R^{*}=0.85^{* *}(P<0.01)$.

less than $-2.5 \mathrm{MPa}$, the total active adjustment increased from 0.5 to $1.3 \mathrm{MPa}$, and sorbitol accounted for $\approx 50 \%$ of the total osmotica.

These results are in partial agreement with those of Ranney et al. (1991) on cherry and by Zhang and Archbold (1991) on strawberry (Fragaria ×ananassa Duch.). Ranney et al. (1991) found that the change in sorbitol concentration alone accounted for the total solute accumulation in potted young cherry and that the concentrations of glucose, fructose, and sucrose did not change. In strawberry, the major solutes detected, in order of their relative contributions to osmotic potential, were glucose, fructose, sucrose, and myo-inositol (Zhang and Archbold, 1991). These results suggest that water stress favors a functional role for sorbitol as an osmoticurn.

There are several possible physiological explanations for the effect of water stress on sorbitol accumulation. Water stress 1) may increase the partitioning of newly fixed carbon into sorbitol; 2) may induce the enzymatic pathways that break down starch and/or sucrose, which increase the substrate (glucose-6- 


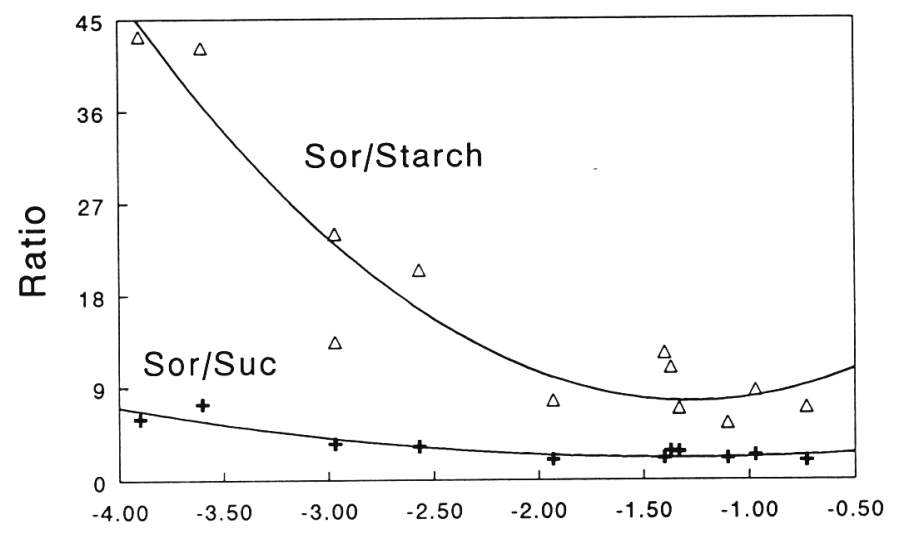

Leaf water potential (MPa)

Fig. 4. Ratios of sorbitol to sucrose and to starch in mature apple leaves 5 days after the imposition of various levels of water stress. The concentrations of carbohydrates were adjusted to $100 \%$ RWC Sor : Suc: $\mathrm{y}=3.31+1.79 \mathrm{x}+0.68 \mathrm{x}^{2}, R^{2}=0.85^{* *}(P<0.01)$. Sor : Starch: $\mathrm{y}=16.22+13.59 \mathrm{x}+5.36 \mathrm{x}^{2}, R^{2}=0.90 * *(P<$ $0.01)$.

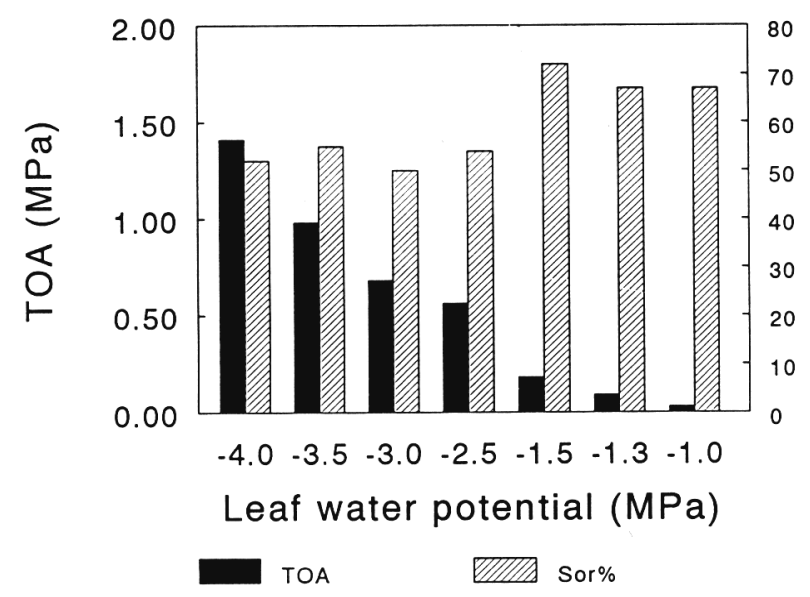

Fig. 5. Total active osmotic adjustment (TOA) and the role of sorbitol in TOA under various stress levels. TOA is the difference between $\psi_{s}$ under stressed conditions and $\psi_{s}$ under well-watered conditions. Percent of sorbitol in TOA is the osmotic adjustment as determined by standard sorbitol solutions divided by TOA of leaf samples.

P) for sorbitol synthesis; 3) may decrease the rate of transport of sorbitol, relative to sucrose, from the leaf.

It is well established that starch is synthesized in the chloroplast, and significant amounts of newly fixed photosynthates are initially partitioned into chloroplast starch (Vassey and Sharkey, 1989). Both sucrose (Daie, 1985) and sorbitol (Loescher, 1987) are the end products of cytosolic enzymatic pathways. The following results suggest how water stress caused the accumulation of sorbitol in the leaves.

Photosynthesis was inhibited and Rs increased as water stress developed in mature apple leaves. A highly positive correlation between $\psi_{w}$ and Pn, and a highly negative correlation between $\psi_{\mathrm{w}}$ and Rs were observed (Fig. 6). When $\psi_{\mathrm{w}}$ was more than $-1.8 \mathrm{MPa}$, the rate of Pn could be maintained at the high level of $10 \mu \mathrm{mol} \cdot \mathrm{m}^{-2} \cdot \mathrm{s}^{-1}$. The rate of Pn decreased dramatically when $\psi_{\text {w }}$ was less than $-1.8 \mathrm{MPa}$, a level below which $\psi_{\mathrm{P}}$ could not be maintained (Fig. 1). These results agree with those reported by Davies and Lakso (1978) for 'Northern Spy' apple

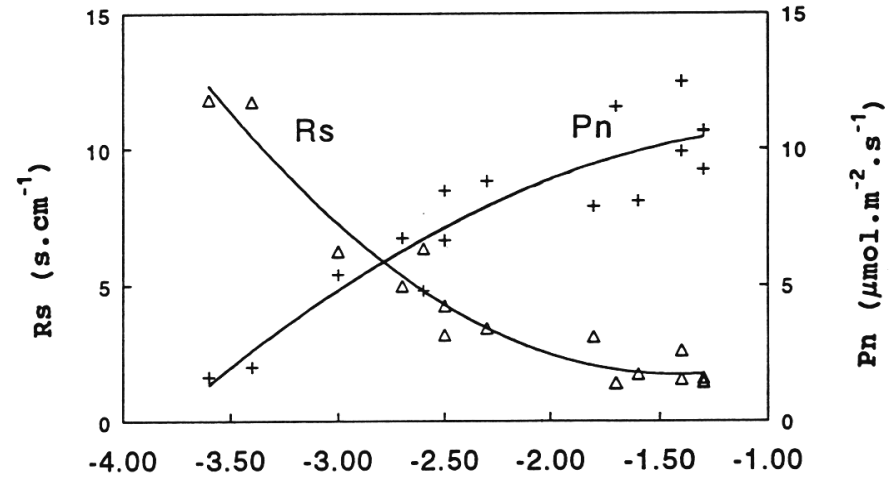

\section{Leaf water Potential (MPa)}

Fig. 6. Effects of water stress on $\mathrm{Pn}$ and Rs in mature apple leaves Pn: $\mathrm{y}=10.43-1.45 \mathrm{x}-1.11 \mathrm{x}^{2}, R^{2}=0.85 * *(P<0.01)$. Rs: $\mathrm{y}=6.21+6.36 \mathrm{x}+2.24 \mathrm{x}^{2}, R^{2}=0.94 * *(P<0.01)$.
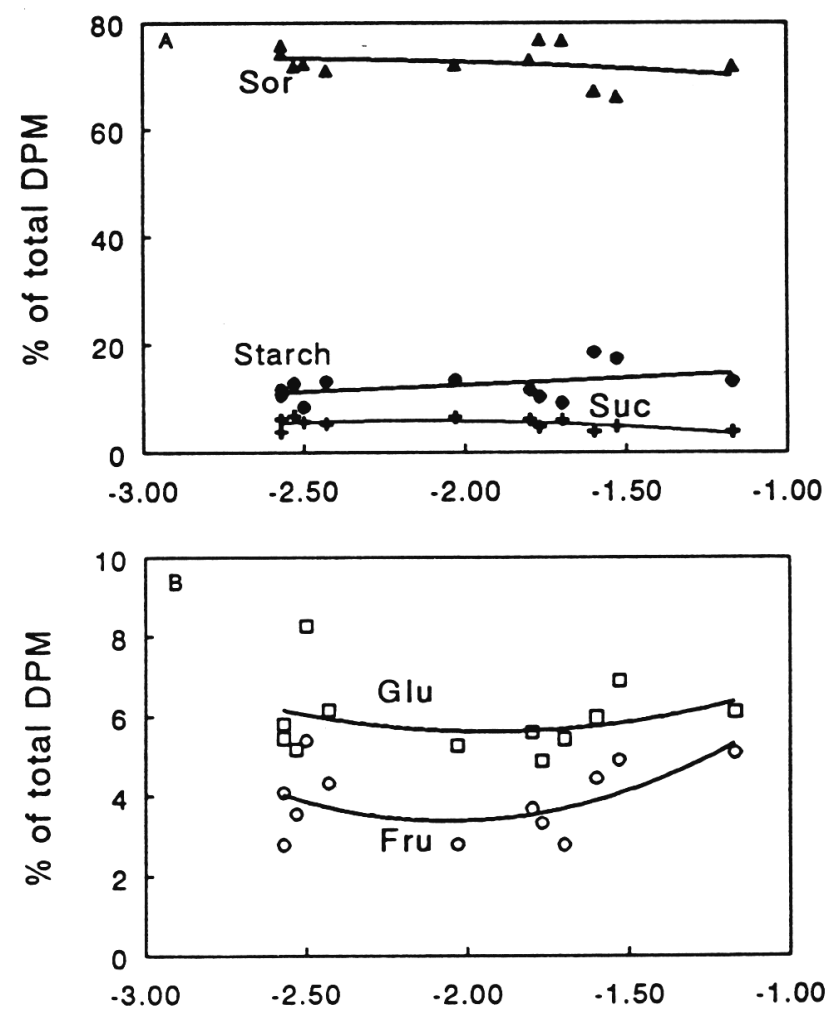

Leaf water Potential (MPa)

Fig. 7. Percentage of each ${ }^{14} \mathrm{C}$-carbohydrate in total ${ }^{14} \mathrm{C} \mathrm{DPM}$ of mature apple leaves at $0 \mathrm{~h}$ after ${ }^{14} \mathrm{CO}_{2}$ labeling under various levels of water stress. Water stress treatments were applied on $3 \mathrm{Feb}$. and ${ }^{14} \mathrm{CO}_{2}$ was fed to mature leaves for $30 \mathrm{~min}$ at 11:30 AM. The leaves were harvested at 12:00 AM on 4 Feb., immediately after the removal of leaf chambers. (A) ${ }^{14} \mathrm{C}$-sorbitol: $\mathrm{y}=63.37-7.44 \mathrm{x}-1.39 \mathrm{x}^{2}$, $R^{2}=0.09(P>0.05) .{ }^{14} \mathrm{C}$-sucrose: $\mathrm{y}=-5.43-10.41 \mathrm{x}-$ $2.41 \mathrm{x}^{2}, R^{2}=0.34(P>0.05) .{ }^{14} \mathrm{C}$-starch: $\mathrm{y}=17.92+2.88 \mathrm{x}+$ $0.08 \mathrm{x}^{2}, R^{2}=0.17(P>0.05)$. (B) ${ }^{14} \mathrm{C}$-glucose: $\mathrm{y}=10.55+$ $5.11 \mathrm{x}+1.32 \mathrm{x}^{2}, R^{2}=0.28(\mathrm{P}>0.05) .{ }^{14} \mathrm{C}$-fructose: $\mathrm{y}=13.81$ $+10.13 \mathrm{x}+2.46 \mathrm{x}^{2}, R^{*}=0.28(P>0.05)$.

seedlings grown in the greenhouse. West and Gaff (1976) found that Rs in apple leaves was independent of $\psi_{w}$ until $\psi_{w}$ fell 

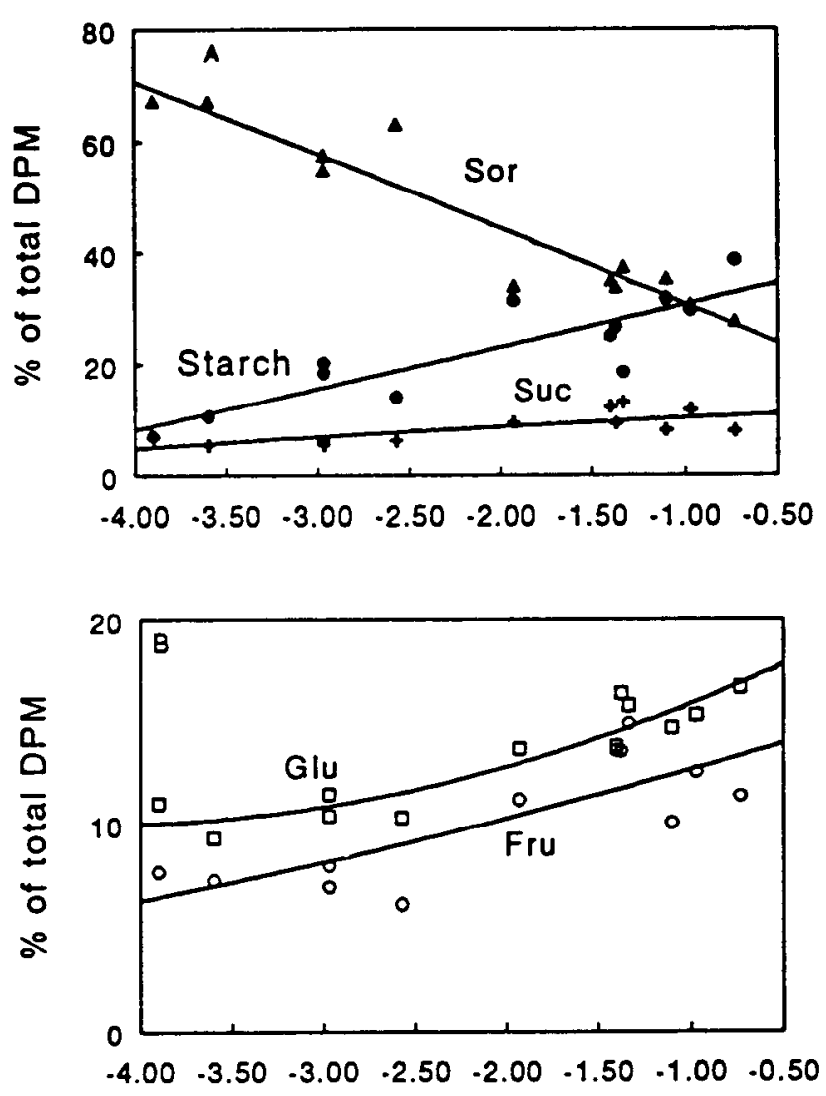

Leaf water potential (MPa)

Fig. 8. Percentage of $\mathrm{W}$-carbohydrates in total ${ }^{14} \mathrm{C} \mathrm{DPM}$ at $96 \mathrm{~h}$ after ${ }^{14} \mathrm{C} \mathrm{O}_{2}$ labeling under various levels of water stress (8 Feb.). Water stress treatments were applied on $3 \mathrm{Feb}$. and ${ }^{14} \mathrm{CO}_{2}$ was fed to mature apple leaves for $30 \mathrm{~min}$ at 11:30 AM on $4 \mathrm{Feb}$. Leaves were harvested at 12:00 AM ( 8 Feb.), $96 \mathrm{~h}$ after removal of leaf chambers. (A) ${ }^{14} \mathrm{C}$-sorbitol: $\mathrm{y}=16.77-14.39 \mathrm{x}-0.22 \mathrm{x}^{2}, R^{2}=$ $0.90 * *(P<0.01) .{ }^{14} \mathrm{C}$-sucrose: $\mathrm{y}=11.62+1.12 \mathrm{x}-0.14 \mathrm{x}^{2}$, $R^{2}=0.05^{* *}(P<0.01)$. W-starch: $\mathrm{y}=38.52+7.80 \mathrm{x}+0.06 \mathrm{x}^{2}$, $R^{2}=0.74 * *(P<0.01)$. (B) ${ }^{14} \mathrm{C}$-glucose: $\mathrm{y}=20.10+4.76 \mathrm{x}+$ $0.56 \mathrm{x}^{2}, R^{2}=0.86^{* *}(P<0.01) .{ }^{14} \mathrm{C}$-fructose: $\mathrm{y}=15.36+2.82 \mathrm{x}$ $+0.14 \mathrm{x}^{2}, R^{2}=0.62 * *(P<0.01)$.

below -1.9 $\mathrm{MPa}$, a similar level as in our result, after which Rs increased dramatically. The ability of apple leaves to maintain Pn rate at $\psi_{\mathrm{w}}$ down to $-2.0 \mathrm{MPa}$ (Davies and Lakso, 1978;
West and Gaff, 1976), or even down to $-3.0 \mathrm{MPa}$ (Lakso, 1979), is well established.

We did not observe a significant effect of water stress on the partitioning of ${ }^{14} \mathrm{C} \mathrm{O}_{2}$ into ${ }^{14} \mathrm{C}$-sucrose, ${ }^{14} \mathrm{C}$-glucose ${ }^{14} \mathrm{C}$-fructose, ${ }^{14} \mathrm{C}$-sorbitol, or ${ }^{14} \mathrm{C}$-starch (Fig. 7) immediately following ${ }^{14} \mathrm{C} \mathrm{O}_{2}$ labeling for $30 \mathrm{~min}$. About $70 \%$ of the recovered ${ }^{14} \mathrm{C}$ was in sorbitol, $15 \%$ in starch, and $5 \%$ in sucrose. Glucose and fructose accounted for $6 \%$ and $4 \%$ of recovered ${ }^{14} \mathrm{C}$, respectively. The effect of water stress on the metabolism of ${ }^{14} \mathrm{C}$ carbohydrates during the $30 \mathrm{~min}$ pulse was not determined.

In contrast, significant correlations between leaf $\psi_{\mathrm{w}}$ and the intraleaf partitioning of ${ }^{14} \mathrm{C}$ were found at 24,48 , and $96 \mathrm{~h}$ after ${ }^{14} \mathrm{CO}_{2}$ labeling. Since the trend was similar at all sampling periods, only the results after $96 \mathrm{~h}$ (Fig. 8) are presented. There were highly significant positive correlations between $\psi_{w}$ and the percentage of ${ }^{14} \mathrm{C}$ in sucrose, glucose, fructose, and starch, and a highly significant negative correlation between $\psi_{\mathrm{w}}$ and percentage of ${ }^{14} \mathrm{C}$-sorbitol. At high $\psi_{\mathrm{w}}$ (more than $-1.0 \mathrm{MPa}$ ), $\approx 30 \%$ of the ${ }^{14} \mathrm{C}$ was found in starch and another $30 \%$ in sorbitol. Glucose and fructose combined accounted for $25 \%$ of the label, with the remaining $15 \%$ being found in sucrose. At $\psi_{w}$ of $-3.5 \mathrm{MPa}, 70 \%$ of the label was recovered in sorbitol. The percentage of ${ }^{14} \mathrm{C}$ found in sucrose, glucose, fructose, and starch was reduced to $<10 \%$ each. In Phaseolus vulgaris (L.), Vassey and Sharkey (1989) observed a similar decline in partitioning of carbohydrates to starch but not to sucrose.

The amount of ${ }^{14} \mathrm{C}$-carbohydrates recovered from the leaves declined rapidly after labeling (Table 1). These data are consistent with active transport of sorbitol from mature leaves. ${ }^{14} \mathrm{C}$ sorbitol disappeared rapidly whether under well watered or stressed conditions, followed by ${ }^{14} \mathrm{C}$-sucrose and ${ }^{14} \mathrm{C}$-starch, while ${ }^{14} \mathrm{C}$ glucose and ${ }^{14} \mathrm{C}$-fructose declined more slowly. Under wellwatered conditions, only $5 \%$ of sorbitol remained in the labeled leaves at $96 \mathrm{~h}$ after labeling, but $24 \%$ in sucrose and starch, and $\approx 28 \%$ in glucose and fructose, respectively. Water stress induced more ${ }^{14} \mathrm{C}$-carbohydrates to accumulate in the labeled leaves. At 96 h, 30, 40, 40, 51, and 56\% of sorbitol, sucrose, starch, glucose, and fructose, respectively, were recovered in water-stressed plants. When compared with well water controls, however, the relative amount of ${ }^{14} \mathrm{C}$-sorbitol remaining in the labeled leaves under water stress was higher than that of any other ${ }^{14} \mathrm{C}$-carbohydrates. The ratio of $\left[{ }^{14} \mathrm{C}-\mathrm{CHO}\right]-{ }_{3.5 \mathrm{MPa}} /\left[{ }^{14} \mathrm{C}\right.$ $\mathrm{CHO}]_{-0.5 \mathrm{MPa}}$ was $\approx 6$ for sorbitol, 2 for sucrose and starch, and $\approx 2$ for glucose and fructose.

The ${ }^{14} \mathrm{C}$-labeling results indicate that water stress does not

Table 1. Relative amounts of ${ }^{14} \mathrm{C}$-carbohydrates remaining in mature leaves at 24,48 , and $96 \mathrm{~h}$ after exposure to a $30 \mathrm{~min}{ }^{14} \mathrm{CO}_{2}$ pulse.

\begin{tabular}{|c|c|c|c|c|c|c|c|c|c|}
\hline \multirow[b]{3}{*}{ Carbohydrate } & \multicolumn{6}{|c|}{$\begin{array}{c}\text { Percentage of }{ }^{14} \mathrm{C} \text { recovered in } 30 \mathrm{~min} \text { pulse } \\
\text { Time after }{ }^{\mathrm{1}} \mathrm{CO}_{2} \text { exposure }(\mathrm{h})\end{array}$} & \multicolumn{3}{|c|}{$\frac{\psi_{W(-3.5)}}{\psi_{W(-0.5)}}$} \\
\hline & \multicolumn{2}{|c|}{$24 \mathrm{~h}$} & \multicolumn{2}{|c|}{$48 \mathrm{~h}$} & \multicolumn{2}{|c|}{$96 \mathrm{~h}$} & \multirow[b]{2}{*}{$24 \mathrm{~h}$} & \multirow[b]{2}{*}{$48 \mathrm{~h}$} & \multirow[b]{2}{*}{$96 \mathrm{~h}$} \\
\hline & $\psi_{W(-0.5)}$ & $\psi_{W(-3.5)}$ & $\psi_{w(-0.5)}$ & $\psi_{w(-3.5)}$ & $\psi_{w(-0.5)}$ & $\psi_{w(-3.5)}$ & & & \\
\hline Sucrose & $60 \mathrm{a}^{\mathrm{y}}$ & $48 \mathrm{ab}$ & $32 \mathrm{a}$ & $46 \mathrm{a}$ & $24 \mathrm{a}$ & $40 \mathrm{a}$ & $0.8 \mathrm{a}$ & $1.4 \mathrm{~b}$ & $1.7 \mathrm{~b}$ \\
\hline Glucose & $56 a b$ & 59 a & $36 a$ & $55 \mathrm{a}$ & $28 \mathrm{a}$ & 51 a & $1.1 \mathrm{a}$ & $1.5 \mathrm{~b}$ & $1.8 \mathrm{~b}$ \\
\hline Fructose & $44 \mathrm{~b}$ & $44 \mathrm{~b}$ & $33 a$ & $60 \mathrm{a}$ & $27 \mathrm{a}$ & $56 a$ & $1.0 \mathrm{a}$ & $1.8 \mathrm{~b}$ & $2.1 \mathrm{~b}$ \\
\hline Sorbitol & $41 \mathrm{~b}$ & $59 a$ & $15 \mathrm{~b}$ & $48 \mathrm{a}$ & $5 \mathrm{~b}$ & $30 \mathrm{~b}$ & $1.4 \mathrm{a}$ & $3.2 \mathrm{a}$ & $6.0 \mathrm{a}$ \\
\hline Starch & $49 \mathrm{~b}$ & $62 \mathrm{a}$ & $26 \mathrm{a}$ & $44 \mathrm{a}$ & $24 \mathrm{a}$ & $40 \mathrm{a}$ & $1.3 \mathrm{a}$ & $1.7 \mathrm{~b}$ & $1.7 \mathrm{~b}$ \\
\hline
\end{tabular}

${ }^{2} \mathrm{DPM}$ of ${ }^{14} \mathrm{C}$ in each carbohydrate recovered immediately following the $30 \mathrm{~min}$ pulse with ${ }^{14} \mathrm{CO}_{2}$ is considered to be 100 and ${ }^{14} \mathrm{C}$ recovered from tissue after 24,48 , or $96 \mathrm{~h}$ is equal to the percentage of ${ }^{14} \mathrm{C}$ recovered in the $30 \mathrm{~min}$ pulse.

'Mean separation within columns by Duncan's multiple range test $(P=0.05)$. 
affect the partitioning of newly fixed assimilates among the sucrose, sorbitol, and starch pathways (Fig. 7), and as such, are not consistent with the hypothesis that water stress increases the partitioning of newly fixed $\mathrm{C}$ into sorbitol. The increase in sorbitol was not associated with rate of $\mathrm{C}$ assimilation since $\mathrm{Pn}$ decreased as water stress developed (Fig. 6). Further, the increase in sorbitol concentration was not associated with the reduced conversion of sorbitol during water stress because sorbitol dehydrogenase (EC 1.18.3.1) activity, the enzyme which converts sorbitol to fructose, is very low in mature leaves (Loescher et al., 1982; Yamaki and Ishikawa, 1986).

However, the increased partitioning of ${ }^{14} \mathrm{C}$ into sorbitol after $96 \mathrm{~h}$ of water stress (Fig. 8, Table 1) is consistent with the hypothesis that water stress decreases the rate of transport of sorbitol, relative to sucrose, from the leaf and the hypothesis that water stress induces the enzymatic pathways that break down starch and/or sucrose, which increase the substrate (glucase-6-P) for sorbitol synthesis. We could not determine whether the sorbitol accumulation under water stress was due to the reduced transport of sorbitol or the increased breakdown of starch and sucrose. The evidence of decreases in concentrations (Fig. 2) and percentage of ${ }^{14} \mathrm{C}$-sucrose and ${ }^{14} \mathrm{C}$-starch (Fig. 8) under water stress, suggest that the breakdown of starch was stimulated by water stress. More breakdown of starch and sucrose into glucose could be a potential factor for further sorbitol synthesis. Nevertheless, the further conversion from glucose to sorbitol under water stress is not clear. If the conversion to sorbitol synthesis were inhibited under water stress, the reduced sorbitol transport from the mature leaves could be the primary source for sorbitol accumlation.

\section{Literature Cited}

Acevedo, E., T.C. Hsiao, and D.W. Henderson. 1971. Immediate and subsequent growth responses of maize leaves to changes in water status. Plant Physiol. 48:631-636.

Barrs, H.D. and P.E. Weatherley. 1962. A re-examination of the relative turgidity technique for estimating water deficits in leaves. Austral. J. Biol. Sci. 15:413-428.

Bieleski, R.L. 1969. Accumulation and translocation of sorbitol in apple phloem. Austral. J. Biol. Sci. 22:611-620.

Bieleski, R.L. and R.J. Redgwell. 1985. Sorbitol versus sucrose as photosynthesis and translocation products in developing apricot leaves. Austral. J. Plant Physiol. 12:657-668.

Cornish, K. and J.A.D. Zeevaart. 1984. Abscisic acid metabolism in relation to water stress and leaf age in Xanthium strumarium. Plant Physiol. 76:1029-1035.

Cutler, J.M., D.W. Rains, and R.S. Loomis. 1977. Role of changes in solute concentration in maintaining favorable water balance in field-grown cotton. Agron. J. 69:773-779.

Daie, J. 1985. Carbohydrate partitioning and metabolism in crops. Hort. Rev. 7:69-108.

Davies, F.S. and A.N. Lakso. 1978. Water relations in apple seedlings: Changes in water potential components, abscisic acid levels and stomatal conductances under irrigated and non-irrigated conditions. J. Amer. Soc. Hort. Sci. 103:310-313.

Davies, F.S. and A.N. Lakso. 1979. Diurnal and seasonal changes in leaf water potential components and elastic properties in response to water stress in apple trees. Physiol. Plant 46:109-114.

Drossopoulos, J.B., A.J. Karamanos, and C.A. Niavis. 1987. Changes in ethanol soluble carbohydrates during the development of two wheat cultivars subjected to different degrees of water stress. J. Bot. 59:173180.

Düring, H. 1985. Osmotic adjustment in grapevines. Acta Hort. 171:315322.

Fanjul, L. and P.H. Rosher. 1984. Effect of water stress on internal water relations of apple leaves. Physiol. Plant. 62:321-328.
Fereres, E., G. Cruz-Romero, G.J. Hoffman, and S.L. Rawlins. 1979. Recovery of orange trees following severe water stress. J. Applied Ecol. 16:833-842.

Goode, J.E. and K.H. Higgs. 1973. Water, osmotic and pressure potential relationships in apple leaves. J. Hort. Sci. 48:203-215.

Handa, S., R.A. Bressan, A.K. Handa, N.C. Carpita, and P.M. Hasegawa. 1983. Solutes contributing to osmotic adjustment in cultured plant cells adapted to water stress. Plant Physiol. 73:834-843.

Hansen, P. and J. Grauslund. 1978. Levels of sorbitol in bleeding sap and in xylem sap in relation to leaf mass and assimilate demand in apple trees. Physiol. Plant. 42:129-133.

Henson, I.E., C.R. Jenson, and N.C. Turner. 1989. Leaf gas exchange and water relations in lupins and wheat. III. Abscisic acid and droughtinduced stomata1 closure. Austral. J. Plant Physiol. 16:429-442.

Hsiao, T.C. 1973. Plant responses to water stress. Annu. Rev. Plant Physiol. 24:519-570.

Hsiao, T.C., E. Acevedo, E. Fereres, and D.W. Henderson. 1976. Stress metabolism - Water stress, growth, and osmotic adjustment. Phil. Trans. Royal Soc. Lond. B. 273:479-500.

Jones, H.J., A.N. Lakso, and J.P. Syvertsen. 1985. Physiological control of water status in temperate and subtropical fruit trees. Hort. Rev. vol. 7:301-344.

Lakso, A.N. 1979. Seasonal changes in stomatal responses to leaf water potential in apple. J. Amer. Soc. Hort. Sci. 104:58-60.

Lakso, A.N. 1983. Morphological and physiological adaptations for maintaining photosynthesis under water stress in apple trees, p. 8593. In: R. Marcelle, H. Clijsters, and M. Van Poucke (eds.). Stress effects on photosynthesis. W. Junk, The Hague.

Lakso, A.N., A.S. Geyer, and S.G. Carpenter. 1984. Seasonal osmotic relations in apple leaves of different ages. J. Amer. Soc. Hort. Sci. 109:544-547.

Landsberg, J.J. and H.G. Jones. 1981. Apple orchards, p. 419-169. In: T.T. Kozlowski (ed.). Water deficits and plant growth, vol. VI. Academic, New York.

Loescher, W.H. 1987. Physiology and metabolism of sugar alcohols in higher plants. Physiol. Plant. 70:553-557.

Loescher, W.H., G.C. Marlow, and R.A. Kennedy. 1982. Sorbitol metabolism and sink-source interconversions in developing apple leaves. Plant Physiol. 70:335-339.

Morgan, J.M. 1984. Osmoregulation and water stress in higher plants. Ann. Rev. Plant Physiol. 35:299-319.

Munns, R. and R. Weir. 1981. Contribution of sugars to osmotic adjustment in elongating and expanded zones of wheat leaves during moderate water deficits at two light levels. Austral. J. Plant Physiol. 8:93-105

Newton, R.J., S. Bhaskaran, J.D. Puryear, and R.H. Smith. 1986. Physiological changes in cultured sorghum cells in response to induced water stress. II. Soluble carbohydrates and organic acids. Plant Physiol. 81:626-629.

Nicolas, M.E., H. Lambers, R.J. Simpson, and M.J. Dalling. 1985. Effects of drought on metabolism and partitioning of carbon in two wheat varieties differing in drought-tolerance. Ann. Bot. 55:727742.

Ranney, T.G., N.L. Bassuk, and T.H. Whitlow. 1991. Osmotic adjustment and solute constituents in leaves and roots of water-stressed cherry (Prunus) trees. J. Amer. Soc. Hort. Sci. 116:684-688.

Rhodes, D., S. Handa, and R.A. Bressan. 1986. Metabolic changes associated with adaptation of plant cells to water stress. Plant Physiol. 82:890-903.

Robinson, S.P., W.J.R. Grant, and B.R. Loveys. 1988. Stomata1 limitation of photosynthesis in abscisic acid-treated and in water stressed leaves measured at elevated $\mathrm{CO}_{2}$. Austral. J. Plant Physiol. 15(4):495503.

Steinberg, S.L., M.J. McFarland, and J.C. Miller, Jr. 1989. Effect of water stress on stomatal conductance and leaf water relations of leaves along current-year branches of peach. Austral. J. Plant. Physiol. 16:549-560.

Swietlik, D. and S.S. Miller. 1983. The effect of paclobutrazol on 
growth and response to water stress of apple seedlings. J. Amer. Soc. Hort. Sci. 108:1076-1080.

Syvertsen, J.P. and L.G. Albrigo. 1980. Seasonal and diurnal citrus leaf and fruit water relations. Bot. Gaz. 141:440-446.

Thakur, P.S. and V.K. Rai. 1980. Water stress effects on maize: Carbohydrate metabolism of resistant and susceptible cultivars of Zea mays L. Biologia Plant. 21(1):50-56.

Turner, N.C. 1979. Drought resistance and adaption to water deficits in crop plants, p. 343-372. In: H. Mussel and R.C. Staples (eds.). Stress physiology in crop plants. Wiley, New York.

Turner, N.C. 1986. Crop water deficits: A decade of progress. Adv. Agron. 39:1-51.

Turner, N.C., J.E. Begg, and M.L. Tonnet. 1978. Osmotic adjustment of sorghum and sunflower crops in response to water deficits and its influence on the water potential at which stomata close. Austral. J. Plant Physiol. 5597-608.
Vassey, T.L. and T.D. Sharkey. 1989. Mild water stress of Phaseolus vulgaris plants leads to reduced starch synthesis and extractable sucrose phosphate synthase activity. Plant Physiol. 89:1066-1070.

Webb, K.L. and J.W.A. Burley. 1962. Sorbitol translocation in apple. Science. 137:766.

West, D.W. and D.F. Gaff. 1976. The effect of leaf water potential, leaf temperature, and light intensity on leaf diffusion resistance and the transpiration of leaves of Malus sylvestris. Physiol. Plant. 38:98104.

Yamaki, S. and K. Ishikawa. 1986. Roles of four sorbitol related enzymes and invertase in the seasonal alteration of sugar metabolism in apple tissue. J. Amer. Soc. Hort. Sci. 111:134-137.

Zhang, B. and D.D. Archbold. 1991. Solute accumulation in leaves of Fragaria chiloensis and $F$. virginiana in response to water deficit stress. HortScience. 26(6):176. (Abstr.) 